\title{
EXPERIMENTAL AND THEORETICAL ASPECTS OF INTERNAL FRICTION ASSOCIATED WITH THE MELTING OF EMBEDDED PARTICLES
}

\author{
A. K. MALHOTRA and D. C. VAN AKEN \\ Department of Materials Science and Engineering, The University of Michigan, Ann Arbor, \\ MI 48109-2136, U.S.A.
}

(Received 2 September 1992; in revised form 24 November 1992)

\begin{abstract}
Internal friction associated with the volume change during melting was studied in an aluminum-16 wt \% indium alloy. This alloy was processed to obtain microstructures consisting of nominally pure indium inclusions embedded in an aluminum matrix. Two sharp internal friction peaks were observed near the indium melting temperature of $156^{\circ} \mathrm{C}$ and both were associated with the formation and growth of liquid nuclei. A general theoretical model for the internal friction was developed which incorporates both the rates of phase deformation and the relaxation of the surrounding matrix. The proposed model considers the effect of the hydrostatic stress generated during melting that initially opposes the transformation. Matrix relaxation around the transforming particles resulting from vacancy flux and dislocation climb contributes an additional frequency dependence to the internal friction. Both the matrix relaxation and the internal friction peak height were found to be dependent upon thermomechanical processing.
\end{abstract}

Résumé-Le frottement intérieur associé avec le changement de volume au cours de la fusion d'un alliage d'aluminium contenant $16 \%$ en poids d'indium est étudié. Cet alliage est préparé afin d'obtenir des microstructures consistant d'inclusions d'indium pure encastrées dans une matrice d'aluminium. Deux pics aigus de frottement intérieur ont été observés prés de $156^{\circ} \mathrm{C}$, température de fusion de l'indium. Ces deux pics ont été associés à la formation et à la croissance des noyaux du liquide. Un model théorique général décrivant le frottement intérieur est établis. Ce model inclut des taux de transformation de phase et de relaxation de la matrice envirronante. Le model proposé prend en considération l'effect de la contrainte hydostatique générée au cours de la fusion et s'opposant initiallement à la transformation. La relaxation de la matrice autour des particles est le résultat d'un flux des lacunes et de la monté des dislocations. Elle ajoute une dépendance de la fréquence du frottement intérieur. La relaxation de la matrice ainsi que la hauteur du pic de frottement intérieur ont été trouvé dépendant des procédés thermomécaniques.

Zusammenfassung--Innere Reibung assoziiert mit der Volumensänderung während dem Schmelzen wurde studiert in einer Aluminium Legierung mit 16 Gewichtsprozent Indium. Diese Legierung wurde prozessiert um Mikrostrukturen zu erhalten, die aus nominal reinen Indium Einschlüssen bestehen welche in einer Aluminium Matrix eingebettet sind. Zwei scharfe innere Reibungs-Höhepunkte wurden beobachtet in der Nähe der Schmelztemperatur von Indium $\left(165^{\circ} \mathrm{C}\right)$, assoziiert mit der Bildung und dem Wachstum von flūssigen Kernen. Ein allgemeines theoretisches Modell für die innere Reibung wurde entwickelt, welches sowohl die Geschwindigkeit der Phasen-Umwandlung als auch die Entspannung der umgebenden Matrix miteinbeschließt. Das vorgeschlagene Modell nimmt in Betracht den Einflu $\beta$ der hydrostatischen Spannungserzeugung während des Schmelzens, welcher anfänglich der Umwandlung entgegenwirkt, Die Entspannung der Matrix in der Umgebung der sich umwandelnden Teilchen, als Folge des Flusses von Fehlstellen und des Aufstiegs von Dislokationen, trägt eine zusätzliche Frequenzabhängigkiet zur inneren Reibung bei. Sowohl die Matrix-Entspannung als auch die Größe der inneren Reibungshöhepunkte zeigten eine Abhängingkeit vom thermomechanischen Prozess.

\section{INTRODUCTION}

Internal friction observed during solid-solid phase transformations has been extensively studied for polymorphic (e.g. [1, 2]) and martensitic reactions (e.g. $[3,4])$. Recently internal friction behavior during a solid-liquid transformation has also been studied and trends similar to the solid-solid diffusionless transformations were reported [5]. Theoretical and phenomenological explanations have been developed to interpret the internal friction during diffusionless transformations in terms of the for- mation of critical nuclei $[1,6]$ and the stress dependent growth of these nuclei $[7,8]$. However, most studies have neglected the possible contribution of a matrix relaxation to the internal friction that accommodates a volume change during transformation. Whether the hydrostatic pressure generated during the formation of the new phase may initially oppose the transformation depends upon the pressuretemperature relationship for thermodynamic equilibrium. In the microstructure of this system, isolated volumes of indium embedded in a matrix of aluminum undergo a volume change upon melting. 
Here the transformation strain is purely hydrostatic resulting from a positive $2 \%$ volume change [9]. The intent of this work was to investigate the internal friction associated with melting and the relaxation of the aluminum matrix.

In 1969, Belko et al. [1] developed a theory to explain the internal friction observed during diffusionless transformations in cobalt-nickel alloys. Here it should be noted that massive transformations, such as melting and polymorphic transformations, may be considered diffusionless since only one atomic jump across the interphase boundary is required for progressive transformation. For shear transformations, the internal friction at small strain amplitudes is given by the following equation

$$
Q^{-1}=\operatorname{Tan} \delta=\frac{\mu \beta a^{2}}{k T \omega}\left(\frac{\mathrm{d} m}{\mathrm{~d} t}\right)
$$

where, $Q^{-1}$ is the loss factor, $\mu$ is the shear modulus, $\beta$ is the volume of the critical nucleus, $a$ is the shear strain produced by the nucleation of the new phase, $[\mathrm{d} m / \mathrm{d} t]$ is the phase transition rate, $k$ is Boltzmann's constant, $T$ is the absolute temperature in degree Kelvins at which $Q^{-1}$ is measured, and $\omega$ is the cyclic oscillation frequency. For the present work, substitution of the bulk modulus, $K$, for $\mu$ and the volume strain for $a$ would provide an analgous expression for melting.

According to Belko et al. [1] the phase transition rate is controlled by the nucleation of the new phase. Thus, a distribution in activation energies between heterogeneous nucleating sites results in a time distribution of material being transformed. A linear dependence upon heating, or cooling, rate was also predicted by replacing the phase transition rate by the product of the temperature rate and the mass transformed as a function of temperature, but experiments have not in general shown this linear dependence [8]. This formulation has however, been extensively used to explain the internal friction produced during martensitic tranformations and has resulted in a general phenomenological approach to the study of diffusionless phase transformations [10]. In 1976, Postnikov et al. [6] proposed that in addition to the internal friction caused by the nucleation of the new phase there might also be a stress dependent contribution from the motion of the interphase boundary. Relationships for the internal friction were only derived for cases of limited frequency and stress ranges. Furthermore, the effect of matrix relaxation on the internal friction behavior of the transformations has not been previously considered.

Previous attempts to study the internal friction associated with melting were those of Mal'tseva and Ivlev [11], Wolfenden and Robinson [12], and Malhotra and Van Aken [5]. Mal'tseva and Ivlev [11] studied a number of nominally pure metals $(\mathrm{Zn}, \mathrm{Cd}, \mathrm{Pb}$, In and $\mathrm{Sn})$ during the onset of melting using a low frequency between 2 and $3 \mathrm{~Hz}$. Only $\mathrm{Sn}$ and $\mathrm{Cd}$ exhibited an internal friction peak which could be associated with the transformation whereas only a rapid drop in the background internal friction during melting was observed for $\mathrm{Zn}$, In, and $\mathrm{Pb}$. In contrast, Wolfenden and Robinson [12] observed internal friction peaks at $40 \mathrm{kHz}$ which were associated with the melting of $\mathrm{Pb}$ inclusions embedded in brass. Sharp internal friction peaks have also been reported by the authors at low frequencies between 0.1 and $2 \mathrm{~Hz}$ for the melting of $\mathrm{Pb}$ and In inclusions embedded in aluminum [5].

\section{EXPERIMENTAL PROCEDURE}

An aluminum-indium alloy with a nominal composition of $16 \mathrm{wt} \%$ indium ( $7 \mathrm{vol} . \%$ ) was prepared by induction melting high purity elements (better than $99.999 \%$ ) in a graphite crucible in an argon atmosphere and solidified by slow cooling in the crucible. Thin sheet material was obtained by cold rolling the cast ingot and annealing in air at $500^{\circ} \mathrm{C}$ for $1 \mathrm{~h}$ followed by water quenching. A variety of matrix grain sizes were obtained by cold working and annealing following a procedure reported by Vyletel
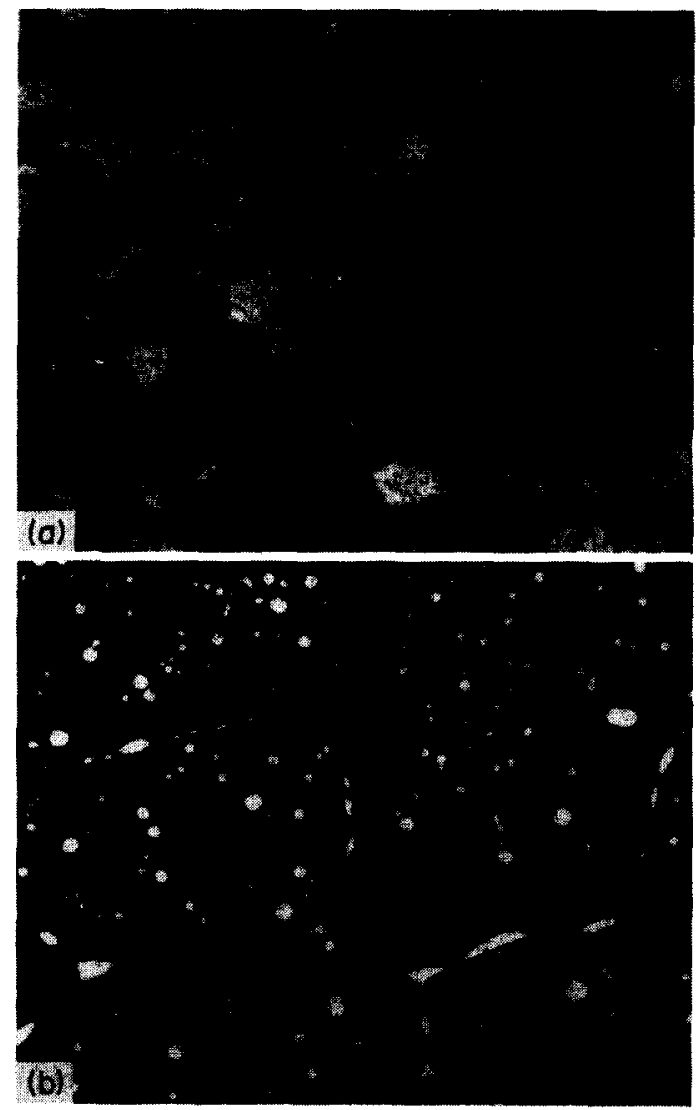

Fig. 1. Microstructure of an Al-16In alloy, induction melted, $80 \%$ cold worked, and recrystallized at $500^{\circ} \mathrm{C}$ for $1 \mathrm{~h}$. (a) Optical micrograph of the sample showing the typical aluminum grain size distribution. (b) Secondary electron image showing the typical distribution of the indium inclusions in the aluminum matrix. Inclusions at grain boundaries are marked by arrows. The smaller spherical particles are embedded in the matrix. 
(a)

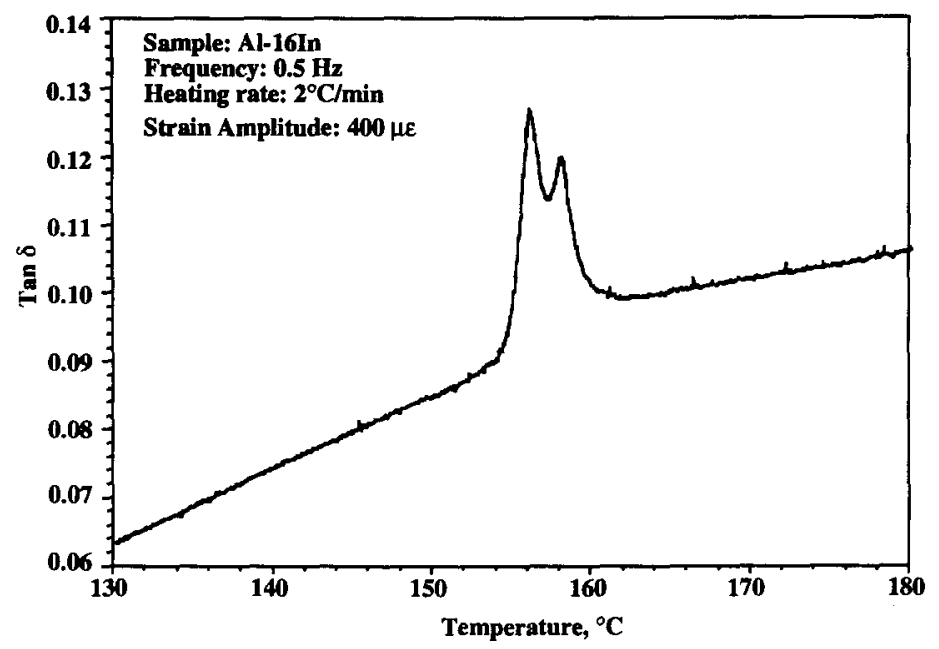

(b)

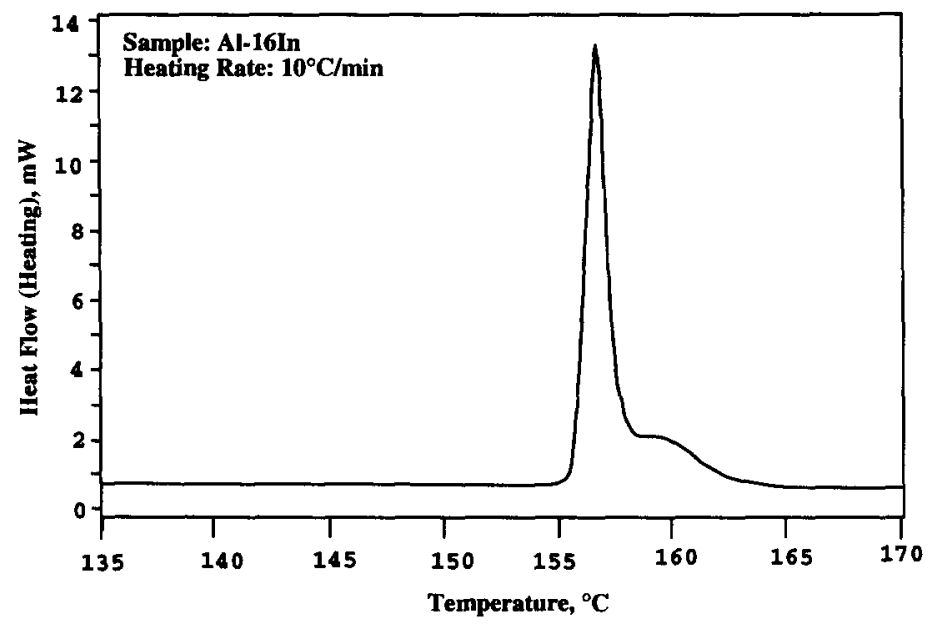

Fig. 2. (a) Typical internal friction spectrum for an Al-16In sample in the vicinity of the indium melting temperature. Two sharp peaks superposed on the background internal friction are due to the melting of indium. (b) Differential scanning calorimetry (DSC) results for the same sample showing a one to one correspondence between the internal friction and the DSC results.

et al. for composite materials [13]. Rectangular test coupons with nominal dimensions $60 \times 10 \times 1.5 \mathrm{~mm}^{3}$ were cut with the long dimension parallel to the rolling direction. A laminated structure of aluminum and indium was also prepared by drilling $5 \mathrm{~mm}$ holes in a block of aluminum and filling them with indium. The block was then cold rolled parallel to the drilled holes, cut into rectangular coupons and annealed. Indium in these laminated samples was exposed on both ends.

A DuPont dynamic mechanical analyzer (DMA), model 983, was used for the internal friction studies. This machine operates in a flexure mode producing both shear and bending stresses in the test coupon. Strain amplitudes reported here were calculated for the specimen surface and represent the maximum strain imposed on the test coupon. Internal friction was measured at fixed frequencies between 0.05 and
$2.0 \mathrm{~Hz}$ and as a function of temperature between 25 and $450^{\circ} \mathrm{C}$. DMA measures internal friction in terms of Tan $\delta$ where the angle $\delta$ has the physical interpretation as the phase angle by which the deflection (strain) lags behind the applied load (stress). The observed internal friction data was corrected for a thermal lag by using the equilibrium eutectic transformation of the Al-In alloy at $156^{\circ} \mathrm{C}$ as a standard temperature reference. Differential scanning calorimetry (DSC) experiments were performed using a Perkin-Elmer model DSC-7 with aluminum pans, a temperature rate of $10^{\circ} \mathrm{C} / \mathrm{min}$, and sample sizes of between 10 and $25 \mathrm{mg}$.

Metallographic samples were prepared by standard polishing techniques. Electrochemical etching with Barker's reagent $\left(4-5 \mathrm{ml}\right.$ of $48 \%-\mathrm{HBF}_{4}$ in $200 \mathrm{ml} \mathrm{H}_{2} \mathrm{O}$ ) revealed the recrystallized aluminum grains after the $500^{\circ} \mathrm{C}$ heat treatment. A critical 
current density of about $0.4 \mathrm{amp} / \mathrm{cm}^{2}$ and an electrode separation of approximately $1.5 \mathrm{~cm}$ were found to provide optimum conditions for etching. Cross-polarized light was used for optical photomicrographs and grain size measurements were made using a random line intercept method. Uncertainties reported in the present work are based upon a Gaussian distribution of the experimentally measured values and represent one standard deviation. Secondary-electron images were obtained with a Hitachi model S-520 scanning electron microscope.

\section{RESULTS}

A typcial microstructure after $80 \%$ cold work and annealing is shown in Fig. 1. Observation of a uniform distribution of equiaxed aluminum grains measuring $65 \pm 10 \mu \mathrm{m}$ in diameter indicates that the samples had undergone a complete recrystallization [see Fig. 1(a)]. There is a duplex distribution of indium inclusions with about $45 \%$ of the total indium distributed in the form of spherical inclusions embedded within the aluminum grains (Type A) and the remaining indium (Type B) distributed in the form of elongated inclusions along the aluminum grain boundaries [see Fig. 1(b)]. Table 1 gives the mean recrystallized grain size of the aluminum matrix and the mean sizes for both types of inclusions.

A typical internal friction spectrum in the vicinity of the melting transition is shown in Fig. 2(a). Two sharp internal friction peaks near the indium melting temperature were found to be superposed on the background internal friction and both peaks were

(a)

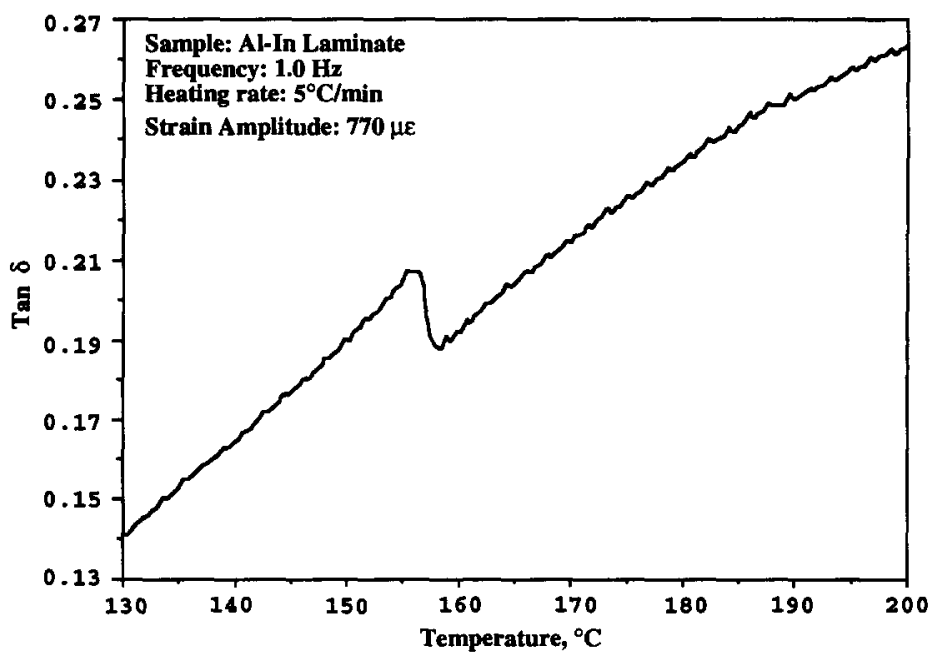

(b)

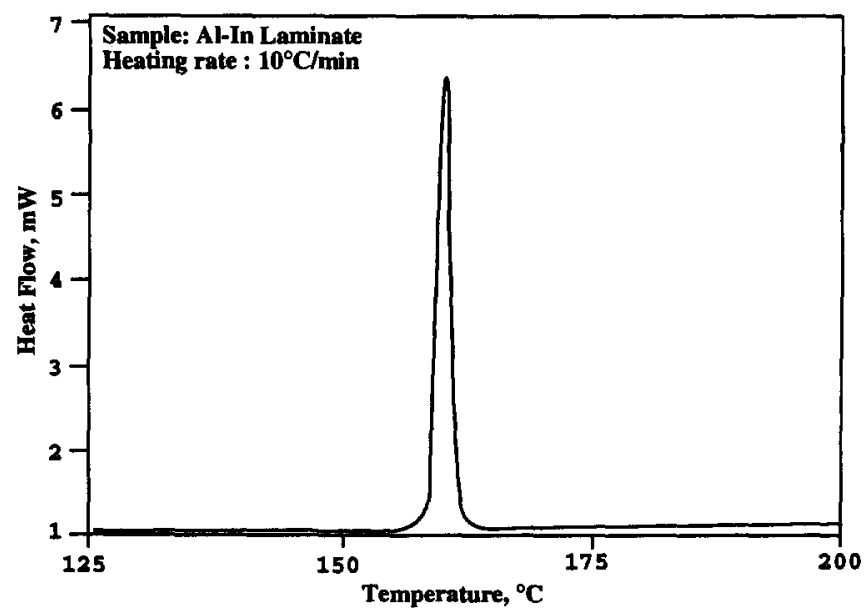

Fig. 3. (a) Internal friction spectrum for a laminated composite of aluminum and indium showing no evidence of an internal friction peak at the indium melting temperature. A drop in the background damping at the indium melting temperature is due to the loss of the solid indium contribution to the total background internal friction. (b) DSC result for an Al-In laminate showing only one peak for the indium melting transformation. 
(a)

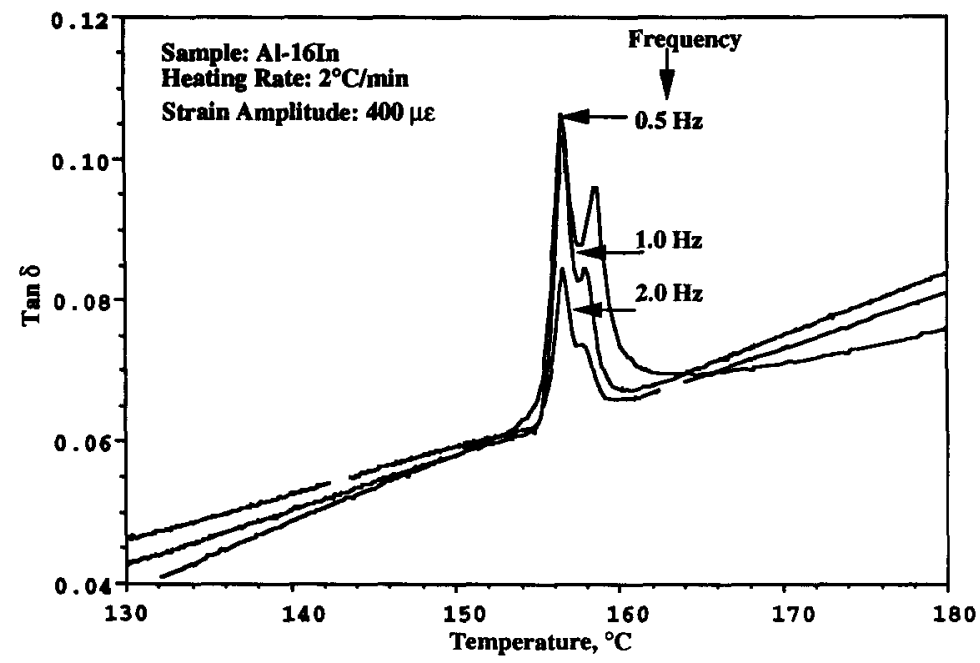

(b)

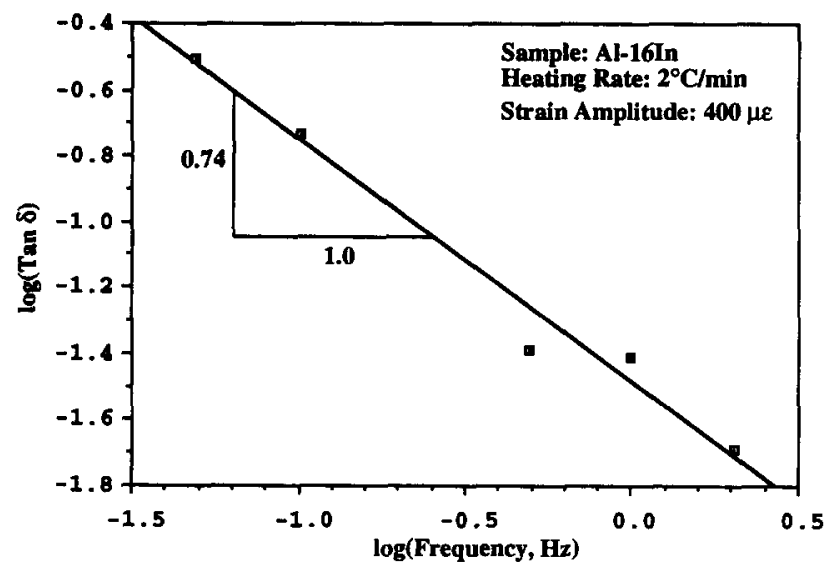

Fig. 4. (a) Internal friction spectra for various frequencies. A decrease in both internal friction peak heights was observed with increasing frequency. (b) A log-log plot of the first melting peak height with frequency shows a straight line with a slope of -0.74 .

Table 1. Summary of quantitative metallographic study for an Al-16In alloy, $80 \%$ cold worked and recrystallized at $500^{\circ} \mathrm{C}$ for $1 \mathrm{~h}$. Indium inclusions are defined as either Type A: spherical embedded, or Type B: elongated grain boundary, inclusions

Average size of spherical

embedded inclusions,

Type A: $1.70 \pm 0.85 \mu \mathrm{m}$

Al matrix grain size

Mean dimensions of

elongated inclusions,

Type B:

$a=6.3 \pm 6 \mu \mathrm{m}$

$b=2.3 \pm 1.2 \mu \mathrm{m}$

$c=8.2 \pm 5.8 \mu \mathrm{m}$

Where the parameters $a, b$ and $c$ are defined as shown below for a typical elongated inclusion

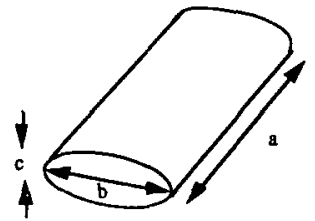

associated with a melting transformation as demonstrated by comparison with differential scanning calorimetry studies [see Fig. 2(b)]. A reasonable value of the heat of fusion of indium was obtained only when both transformation peaks were considered. An elevation of $3^{\circ} \mathrm{C}$ in the melting of a portion of indium is apparent. A comparison of the results from the two techniques [Fig. 2(a,b)] shows that the internal friction peak height is not in direct proportion to the amount of indium transformed. A larger internal friction effect per unit of mass transformed appears to be associated with the higher temperature melting event.

In contrast, the laminated material showed no defined internal friction peak and only one peak was observed in the calorimetry study [see Fig. 3(a, b)]. It should also be noted that some indium was expelled from the laminated sample during the test. This observation may be explained by the positive volume change and subsequent expulsion from the exposed 
ends upon melting. The apparent decrease in damping after melting has been previously discussed by the authors as resulting from the loss of the damping contribution from solid indium to the total high temperature background damping [5, 14]. Thus, like the results of Mal'tseva and Ivlev [11] the internal friction peak is not caused by the melting per se, rather it is attributed to the necessary volume accommodation.

Test-frequency and heating-rate dependences of the internal friction peak height were examined as independent variables. In these studies, only the height of the first internal friction peak was considered because the lower effective instrument data acquisition rate would not permit good peak to peak resolution at higher heating rates. The peak height decreased with increasing frequency in the range of 0.05 to $2 \mathrm{~Hz}$ for a constant heating rate of $2^{\circ} \mathrm{C}$ per min [see Fig. 4(a)]. Equation (1) predicts that $\operatorname{Tan} \delta$ is inversely proportional to frequency, but a plot of $\log \operatorname{Tan} \delta$ vs $\log$ of frequency has a slope of -0.74 [see Fig. 4(b)]. A linear dependence of the internal friction peak height on heating rate was observed
Table 2. Summary of quantitative metallographic study for a strain annealed material. Indium inclusions are defined as either Type A: spherical embedded, or Type B: elongated grain boundary, inclusions. Parameters $a, b$ and $c$ are defined in Table 1

Average size of spherical

embedded inclusions,

Type A: $3.0 \pm 1.7 \mu \mathrm{m}$

Al matrix grain size:

Mean dimensions of

elongated inclusions,

Type B:

$a=12.4 \pm 8.9 \mu \mathrm{m}$

$b=4.8 \pm 2.7 \mu \mathrm{m}$

$c=13.4 \pm 7.8 \mu \mathrm{m}$

Total area of Type $A$ inclusions

Total area of Type B inclusions

$=1.04$

when the heating rate was varied between $0.5-6^{\circ} \mathrm{C}$ per min [see Fig. $5(a, b)$ ].

Interestingly, the peak height of the internal friction was found to be dependent upon thermomechanical processing. For example, the internal friction peak height decreased when the as annealed material was given an additional $21 \%$ cold work (see Fig. 6). Both internal friction peaks were diminished as a result of cold working, but the first peak was more strongly affected. In another experiment the grain size of the aluminum matrix was coarsened by

(a)

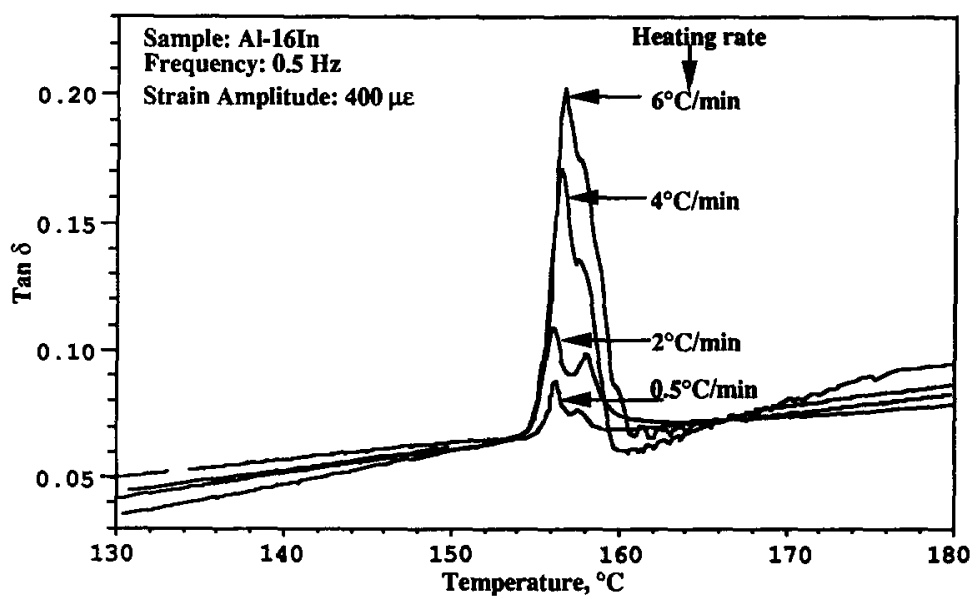

(b)

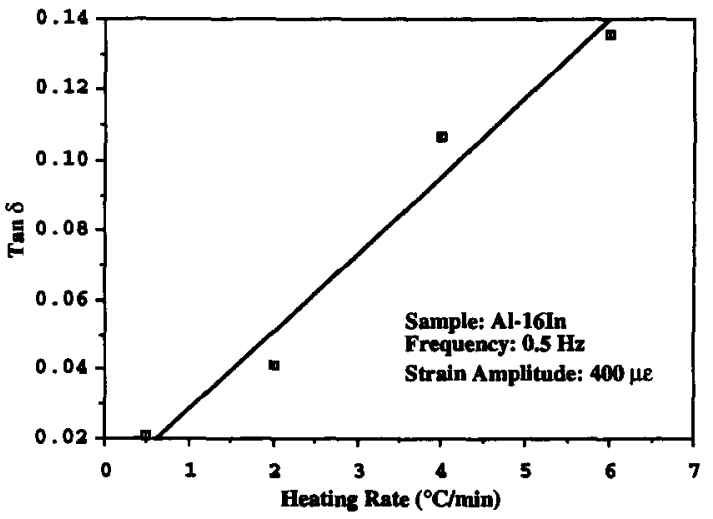

Fig. 5. (a) Results of a heating rate variation study for an Al-16In sample. An increase of the internal friction peak height with increasing heating rates was observed. (b) A plot of the first peak height vs heating rate shows a linear correlation to the heating rate. 


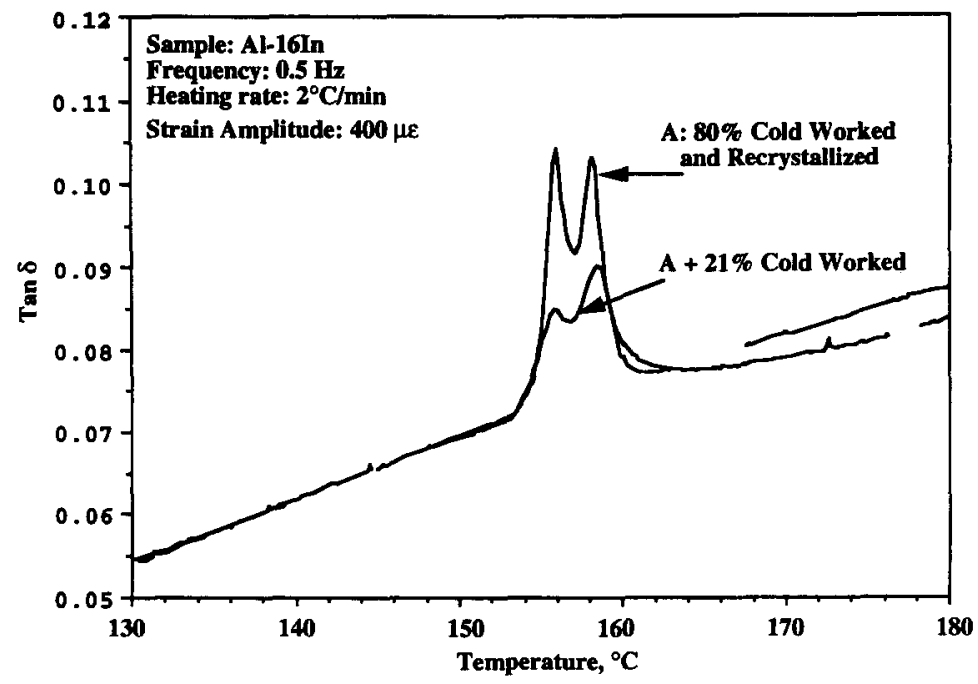

Fig. 6. Internal friction results for the Al-16In sample before and after a $21 \%$ reduction in thickness. A decrease in the internal friction peak height was observed for both transformation peaks in the cold worked sample.
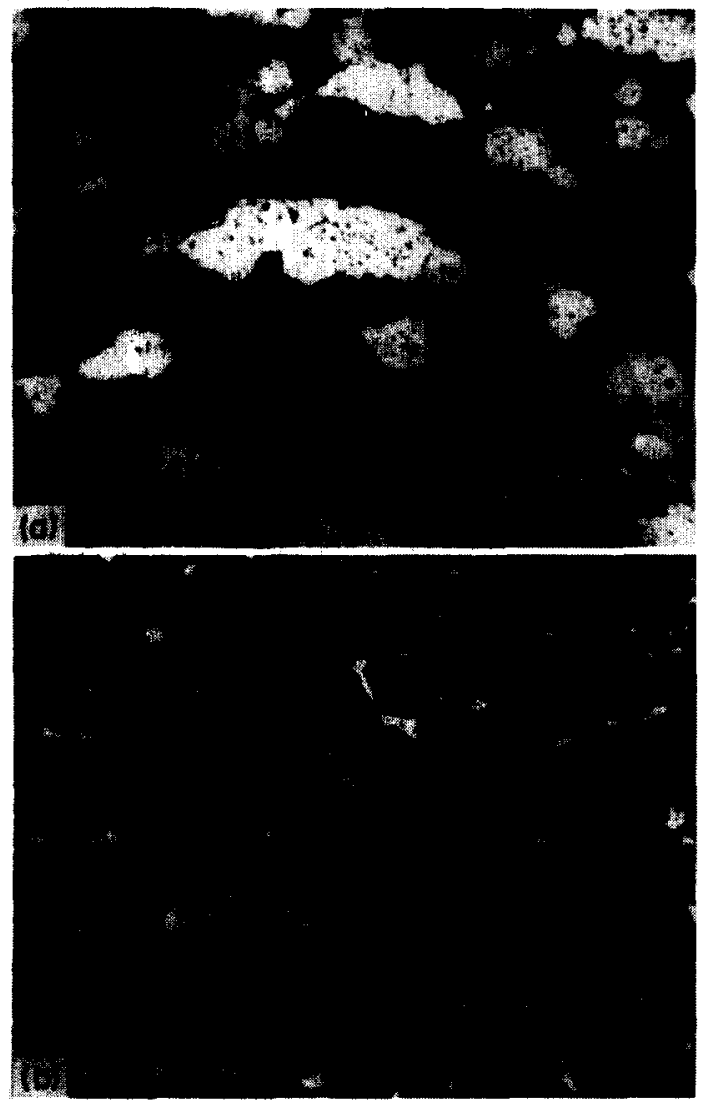

Fig. 7. Microstructure of an Al-16In sample after a strain annealing treatment. The grain size was doubled by cold working $6 \%$ and annealing at $500^{\circ} \mathrm{C}$ for $1 \mathrm{~h}$. (a) Optical micrograph of the sample showing the typical aluminum grain size distribution. (b) Secondary electron image showing the typical distribution of the indium inclusions in the aluminum matrix. Inclusions at grain boundaries are marked by arrows. The smaller spherical particles are embedded in the matrix. strain annealing. After annealing, an additional 6\% cold work was used to induce a second recrystallization event $\left(1 \mathrm{~h}\right.$ at $\left.500^{\circ} \mathrm{C}\right)$ and a final grain diameter of $114 \pm 60 \mu \mathrm{m}$ was obtained (see Fig. 7). Coarsening of the indium particles was also observed, the mean particle size nearly doubled and the ratio of indium embedded within the aluminum grains increased by $14 \%$ (see Table 2). The change in microstructure produced two changes in the character of the internal friction. First the internal friction peak height was increased for both peaks and second, the temperature difference between the two peaks was decreased (see Fig. 8).

\section{DISCUSSION}

The results presented here and those previously presented by the authors [5] along with the results of Mal'tseva and Ivlev [11], and Wolfenden and Robinson [12] suggest that an internal friction peak associated with melting will only be observed when the melting phase is dispersed and fully embedded in a second phase. This would suggest that the internal friction is not directly associated with just the process of forming critical sized nuclei since this would occur regardless of whether the indium were embedded or not. Indeed, the frequency dependence observed in this study deviates from that predicted by equation (1) and the relationship between the amount of mass transformed and the observed peak height also appears to be more complicated. One possible explanation for the observed results is that the internal friction is also related to the accommodation strain in the matrix rather than just to the mechanics of melting, i.e. nucleation and interface motion $[1,2,4,6]$. Here, the hydrostatic strain would be accommodated by either the motion of edge dislocations, or the migration of vacancies towards the 


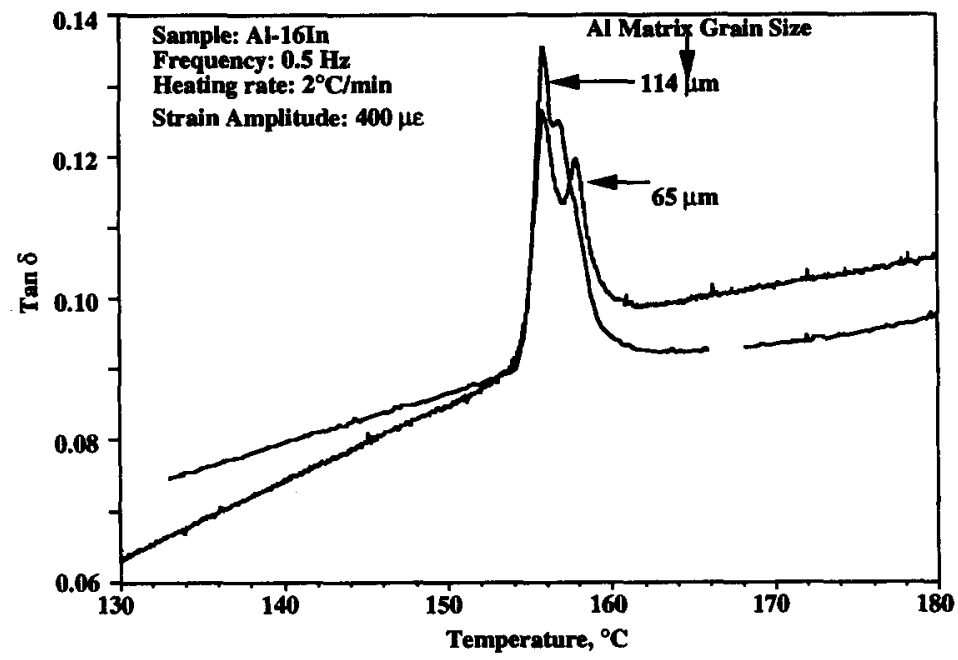

Fig. 8. Internal friction results for $\mathrm{Al}-16 \mathrm{In}$ sample before and after a strain annealing treatment. An increase in the internal friction peak height was observed for both peaks in the strain annealed sample.

transforming inclusion and a relaxation time would then be associated with the motion of these defects. An internal friction effect would then be expected as the matrix accommodates changes in the volume as critical sized nuclei are either created and destroyed or as the liquid-solid interface oscillates during the transformation or both. The relaxation time would also depend upon the physical location of the inclusion and it would be expected that grain boundary diffusion would lead to shorter relaxation times for inclusions located at grain boundaries than for embedded particles where dislocation pipe diffusion and bulk diffusion processes would be required. Furthermore, a smaller grain size or the addition of a small amount of cold work might therefore be expected to reduce the relaxation time by introducing shortcircuit diffusion paths through grain boundaries or dislocation cores, respectively. Although the inclusion size would not affect the transformation strain it would affect the relaxation time. An increase in the inclusion size would produce a corresponding increase in relaxation time since a larger number of defects would be required to migrate longer distances. A general expression for the relaxation of a hydrostatic stress acting on an embedded inclusion with time has been derived in the Appendix.

A model for the observed internal friction for the case of uniaxial applied strain can be developed by considering the volume transformation strain as the anelastic strain associated with the transformation. If at a given time $t$ the mass of indium melted in a sample with volume $V$ is $m(t)$ then the anelastic strain due to melting would be

$$
\epsilon_{\mathrm{an}}(t)=\frac{m(t) \epsilon_{\mathrm{h} 0}}{3 \rho V}
$$

where $\rho$ is the density of indium and $\epsilon_{\mathrm{ho}}$ is the constrained hydrostatic strain generated due to the volume change upon melting. Here it should be noted that if the strain is not constrained the transformation will not produce an internal friction effect. If in an infinitesimally small time interval $\mathrm{d} t$ the amount of indium melted is $\mathrm{d} m(t)$ then the corresponding anelastic strain would be given as

$$
\mathrm{d} \epsilon_{\mathrm{an}}=\frac{\epsilon_{\mathrm{h} 0} \mathrm{~d} m(t)}{3 \rho V} .
$$

The amount of indium melted, $\mathrm{d} m(t)$, will be dependent upon the applied heating rate but opposed by the misfit hydrostatic pressure imposed on the melting inclusion by the matrix. In the present case the increased pressure will raise the melting point [15]. Thus, rather than considering $\mathrm{d} m(t)$ a function of the temperature, $T$, we propose that it is a function of $\Delta T=T-T_{\mathrm{m}}$, where $T_{\mathrm{m}}$ is the pressure-dependent melting temperature and may be expressed by

$$
\mathrm{d} m(t)=\frac{\partial m}{\partial \Delta T} \frac{\partial \Delta T}{\partial T} \mathrm{~d} t .
$$

Substituting the expression for $\Delta T$ in equation (4) we have

$$
\mathrm{d} m(t)=\frac{\partial m}{\partial \Delta T}\left\{\frac{\partial T}{\partial t}-\frac{\partial T_{\mathrm{m}}}{\partial \sigma_{\mathrm{h}}} \frac{\partial \sigma_{\mathrm{h}}}{\partial t}\right\} \mathrm{d} t .
$$

Here the term $\partial T_{\mathrm{m}} / \partial \sigma_{\mathrm{h}}$ is a materials parameter derived from the equilibrium pressure-temperature relationship for melting. Assuming the matrix to be a standard anelastic solid [16], the hydrostatic stress in the matrix would relax with time and the expression for the stress relaxation would be of the form

$$
\frac{\partial \sigma_{\mathrm{h}}}{\partial t}=-\frac{\Delta \sigma_{\mathrm{h} 0}}{\tau} \exp \left(-\frac{t}{\tau}\right)
$$

where $\Delta \sigma_{\mathrm{b} 0}$ is the net amount of the hydrostatic stress relaxed and $\tau$ is the relaxation time of the stress in the matrix. From equations (3), (5) and (6) we get

$$
\begin{aligned}
\mathrm{d} \epsilon_{\mathrm{an}}(t)=\frac{\epsilon_{\mathrm{b} 0}}{3 \rho V} \frac{\partial m}{\partial \Delta T} & \left\{\frac{\partial T}{\partial t}\right. \\
+ & \left.\frac{\partial T_{\mathrm{m}}}{\partial \sigma_{\mathrm{h}}} \frac{\Delta \sigma_{\mathrm{h} 0}}{\tau} \exp \left(-\frac{t}{\tau}\right)\right\} \mathrm{d} t .
\end{aligned}
$$


If the applied stress is sinusoidal and of the form $\sigma(t)=\sigma_{0} \sin \omega t$, then the internal friction during a melting transformation can be calculated from the following definitions [16]

$$
\begin{aligned}
\operatorname{Tan} \delta & =\frac{\Delta W}{2 \pi W} \\
\Delta W & =\oint \sigma \mathrm{d} \epsilon_{\mathrm{an}}
\end{aligned}
$$

where $\Delta W$ is the energy dissipated per cycle and $W$ is the maximum energy stored per cycle, i.e. $W=\sigma_{0}^{2} / 2 E_{\mathrm{m}}$ where $E_{\mathrm{m}}$ is the Young's modulus of the sample. From equations (7), (8) and (9) the internal friction during a melting transformation is given as

$$
\begin{aligned}
\operatorname{Tan} \delta= & \frac{\epsilon_{\mathrm{h} 0} E_{\mathrm{m}}}{3 \pi \rho V \sigma_{0}} \frac{\dot{c} m}{\partial \Delta T}\left\{\frac{4}{\omega} \frac{\partial T}{\partial t}+\frac{\partial T_{\mathrm{m}}}{\partial \sigma_{\mathrm{h}}} \frac{\Delta \sigma_{\mathrm{h} 0}}{1+\omega^{2} \tau^{2}}(\omega \tau\right. \\
& +2 \mathrm{e}^{-\pi / 2 \omega \tau t}+2 \omega \tau \mathrm{e}^{-\pi / \omega \tau}+2 \mathrm{e}^{-3 \pi / 2 \omega \tau} \\
& \left.\left.+\omega \tau \mathrm{e}^{-2 \pi / \omega \tau}\right)\right\}
\end{aligned}
$$

Equation (10) may be greatly simplified by considering low frequency tests on the order of one Hertz and situations where $\omega \tau$ is either much less, or much greater, than $\pi$. For a short relaxation time, as might be expected for inclusions sitting on grain boundaries, equation (10) would be simplified to the following

$$
\operatorname{Tan} \delta=\frac{\epsilon_{\mathrm{h} 0} E_{\mathrm{m}}}{3 \pi \rho V \sigma_{0}} \frac{\partial m}{\partial \Delta T}\left\{\frac{4}{\omega} \frac{\partial T}{\partial t}+\frac{\partial T_{\mathrm{m}}}{\partial \sigma_{\mathrm{h}}} \Delta \sigma_{\mathrm{h} 0} \omega \tau\right\} .
$$

For a slow relaxation of the misfit stresses as might be true for inclusions embedded within aluminum grains, $\omega \tau$ would be much greater than $\pi$, and equation (10) would reduce to

$$
\operatorname{Tan} \delta=\frac{\epsilon_{\mathrm{h} 0} E_{\mathrm{m}}}{3 \pi \rho V \sigma_{0}} \frac{\partial m}{\hat{c} \Delta T}\left\{\frac{4}{\omega} \frac{\partial T}{\partial t}+\frac{\partial T_{\mathrm{m}}}{\partial \sigma_{\mathrm{h}}} \frac{4 \Delta \sigma_{\mathrm{h} 0}}{\omega \tau}\right\} .
$$

For the present case of melting transformation of indium the term $\hat{c} T_{\mathrm{m}} / \partial \sigma_{\mathrm{h}}$ will have a negative value of approximately $25.4 \times 10^{-6}{ }^{\circ} \mathrm{C} \mathrm{m}^{2} / \mathrm{N}$ [15]. This would imply that $\operatorname{Tan} \delta$ will decrease linearly with an increase of the relaxation time for very small values of the product $\omega \tau$ as predicted by equation (11). For very large values of the product, $\omega \tau$, equation (12) predicts that $\operatorname{Tan} \delta$ will increase with the relaxation time. Thus the intersection of the $\operatorname{Tan} \delta$ curves as predicted by equations (11) and (12) will result in a minimum with respect to $\tau$. A calculation of the $\operatorname{Tan} \delta$ using the parameter values shown in Table 3 can be easily made from equations (10), (11) or (12). For a relaxation time of $3.5 \times 10^{6} \mathrm{~s}$ calculated in the Appendix for the inclusions embedded within aluminum grains assuming bulk diffusion a $\operatorname{Tan} \delta$ of 0.01 was obtained using equation (12). If the relaxation time is reduced by two orders of magnitude due to the introduction of dislocations as would be the case
Table 3. Typical values of various parameters used for calculating the relaxation time in equations (10)-(12)

\begin{tabular}{rlrl}
$\epsilon_{\mathrm{n}}$ & $=0.02$ & $\partial T_{\mathrm{m}} / \partial \sigma_{\mathrm{h}}$ & $=25.4 \times 10^{-6} \mathrm{~m}^{2}{ }^{\circ} \mathrm{C} / \mathrm{N}$ \\
$E_{\mathrm{m}}$ & $=67 \times 10^{9} \mathrm{~N} / \mathrm{m}^{2}$ & $\sigma_{0}$ & $=5 \times 10^{6} \mathrm{~N} / \mathrm{m}^{2}$ \\
$\rho$ & $=7000 \mathrm{~kg} / \mathrm{m}^{2}$ & $V$ & $=9 \times 10^{-7} \mathrm{~m}^{3}$ \\
$\partial T / \partial t$ & $=0.033^{\circ} \mathrm{C} / \mathrm{s}$ & $\Delta T$ & $=8^{\circ} \mathrm{C}$ \\
$\omega$ & $=3.14$ cycles $/ \mathrm{s}$ & $m$ & $=V^{*} V_{l}^{*} \rho=441 \times 10^{-6} \mathrm{~kg}$ \\
\hline
\end{tabular}

when the sample is cold worked, then the Tan $\delta$ using equation (12) is calculated to be about 0.008 . This decrease in $\operatorname{Tan} \delta$ is in agreement with the experimental results shown in Fig. 6.

Of general interest is the frequency dependence of each case when compared to the experimental results presented in Fig. 4. If we assume that the first internal friction peak observed represents only the inclusions at grain boundaries then equation (11) would predict an $\omega^{n}$ dependency with $n$ greater than -1 as was observed in Fig. 4(b). In contrast, if the frequency dependence of the second peak is examined a $\omega^{-1}$ dependence may be observed and this is in agreement with equation (12). We believe that this second peak is associated with the smaller indium inclusions that are fully embedded in the matrix.

In closure, we would like to make some general cautionary comments about the model presented. First, and perhaps most important, is that the relaxation time derived in the Appendix does not take into account the possibility of the solid indium relaxing around the liquid nucleus. It would be expected that in larger inclusions a greater portion of the hydrostatic stress change would be accommodated by the low bulk modulus of the indium. This fact may explain why the second internal friction peak is more strongly dependent upon the amount of indium mass transformed. Furthermore, this may also explain why a transformation peak is not observed in either the laminate studied in the present work or when a pure indium sample was studied by Mal'tseva and Ivlev [11]. Secondly, the stress dependence of the internal friction peak was previously reported by the authors to show a $\sigma_{0}^{-0.5}$ dependence [5] rather than a simple inverse relationship predicted by the present model. The model presented assumes that neither the matrix or the inclusion behaves in a viscoelastic manner and this would certainly not hold true for solid indium near its melting point.

\section{CONCLUSIONS}

A theoretical model was presented that describes the internal friction behavior observed during the melting of embedded inclusions. The present model is in agreement with the previous models developed for diffusionless first order transformations in that it predicts a linear dependence upon the heating rate. However, the frequency dependence of the new model is strongly dependent upon the relaxation time of the matrix. As a result a more complex dependence upon the test frequency was predicted and is in qualitative agreement with the experimental results. 
Acknowledgements-This work has been funded in part by the Office of Naval Research and the David Taylor Research Center under Contracts 87-K-0452 and 91-J-1894. The technical monitors were Dr D. E. Polk and Dr L. Kabacoff, respectively. The authors would also like to thank Professor D. J. Srolovitz at the University of Michigan for helpful suggestions in the development of the theoretical models for the internal friction and the relaxation time.

\section{REFERENCES}

1. V. N. Belko, B. M. Darinsky, V. S. Postnikov and I. M. Sharshakov, Fiz. Metall. 27, 140 (1969).

2. S. A. Gridnev, B. M. Darinskiy and V. S. Postnikov, Fiz. Him. Obrab. Mater. 5, 99 (1969).

3. S. Koshimizu and W. Benoit, J. Physique 43, C4-679 (1982).

4. J. F. Delorme, R. Schmid, M. Robin and P. Gobin, J. Physique 32, C2(7)-101 (1971)

5. A. K. Malhotra and D. C. Van Aken, Mechanics and Mechanisms of Materials Damping, ASTM STP 1169 (edited by V. K. Kinra and A. Wolfenden), p. 262. American Society for Testing and Materials, Pa (1992).

6. V. S. Postnikov, S. A. Gridnev, B. M. Darinskiy and I. M. Sharshakov, IL Nuovo Cimento 33B, 324 (1976).

7. W. Dejonghe, R. de Batist and L. Delaey, Scripta metall. 10, 1125 (1976)

8. J. Zhang and X. Li, Chin. Phys. 8, 309 (1988).

9. W. Paul and D. M. Werschauer, Solids Under Pressure, p. 314. McGraw-Hill, New York (1963).

10. R. de Batist, J. Physique 44, C9-39 (1983).

11. G. K. Mal'tseva and V. I. Ivlev, Fiz. Metall. 27, 354 (1969).

12. A. Wolfenden and W. H. Robinson, Acta metall. 25, 823 (1977).

13. G. M. Vyletel, P. E. Krajewski, D. C. Van Aken, J. W. Jones and J. E. Allison, Scripta metall. mater. 27, 549 (1992).

14. A. K. Malhotra and D. C. Van Aken, Metall. Trans. A, in press.

15. W. Paul and D. M. Werschauer, Solids Under Pressure, p. 171. McGraw-Hill, New York (1963).

16. A. S. Norwick and B. S. Berry, Anelastic Relaxation in Crystalline Solids, p. 14. Academic Press, New York (1972).

17. D. R. Uhlmann, J. Non-Cryst. Solids 41, 347 (1980).

\section{APPENDIX}

An expression for the matrix relaxation of a hydrostatic stress imposed by a misfitting inclusion may be derived as follows:

Let $V_{\mathrm{p}}$ be the initial volume of a hole of radius $R$ in the matrix and $V_{\mathrm{p}}+\Delta V_{\mathrm{p}}$ is the volume of a particle of radius $R+\Delta R$ embedded in this hole, then the total hydrostatic strain, $\epsilon_{\mathrm{h} 0}$, which is to be relaxed is

$$
\epsilon_{\mathrm{hO}}=\frac{\Delta V_{\mathrm{p}}}{3 V_{\mathrm{p}}}=\frac{\Delta R}{R} .
$$

The total number of matrix atoms which are to be moved from the interphase region will then be given by

$$
N=\frac{\Delta V_{\mathrm{p}}}{\Omega}
$$

where $\boldsymbol{\Omega}$ is the atomic volume. It at a given time $t$ there is a change in strain of $\delta \epsilon_{\mathrm{h}}$ from $\epsilon_{\mathrm{h} 0}$, the number of atoms which must have moved is given from equation (Al) and (A2) as

$$
\delta N=\frac{3 V_{\mathrm{p}} \delta \epsilon_{\mathrm{h}}}{\Omega} .
$$

The hydrostatic stress acting on the matrix surrounding the inclusion under a strain $\epsilon_{\mathrm{ho}}$ [17] is

$$
\sigma_{\mathrm{h} 0}=\frac{36 K_{\mathrm{p}} \mu_{\mathrm{m}}}{3 K_{\mathrm{p}}+4 \mu_{\mathrm{m}}} \epsilon_{\mathrm{ho}}
$$

where $K_{\mathrm{p}}$ and $\mu_{\mathrm{m}}$ are the bulk modulus of the inclusion and shear modulus of the matrix, respectively. Therefore the work done in moving $\delta N$ atoms from the interphase region is

$$
\delta W=3 \sigma_{\mathrm{h} 0} \delta \epsilon_{\mathrm{h} 0} V_{\mathrm{p}} .
$$

If these atoms are to be moved to a distance $r$ from the interphase region then the force $F$ acting on each atom is given as

$$
F=-\frac{\delta W}{r \delta N}
$$

and from (A5) and (A6)

$$
\sigma_{\mathrm{h} 0}=\left(\frac{36 K_{\mathrm{p}} \mu_{\mathrm{m}}}{3 K_{\mathrm{p}}+4 \mu_{\mathrm{m}}}\right) \frac{\epsilon_{\mathrm{h} 0} \Omega}{r} .
$$

According to Einstein's relation the drift velocity of atoms under a force $F$ will be given as

$$
v=-\left(\frac{D}{k T}\right) F=-\frac{D \Omega}{k T r}\left(\frac{36 K_{\mathrm{p}} \mu_{\mathrm{m}}}{3 K_{\mathrm{p}}+4 \mu_{\mathrm{m}}}\right) \epsilon_{\mathrm{ho}}
$$

where $D$ is the appropriate diffusivity, $k$ is the Boltzmann's constant, and $T$ is absolute temperature in $\mathrm{K}$. The crosssectional area through which the atoms are diffusing is $A_{\mathrm{p}}=4 \pi R^{2}$, and during the time interval $\delta t$ the number of atoms moved will be

$$
\delta N=\left(\frac{4 \pi R^{2}}{\Omega}\right) v \delta r .
$$

From (A3), (A8) and (A9)

$$
\frac{\delta \epsilon_{\mathrm{h} 0}}{\delta t}=-\frac{\epsilon_{\mathrm{h} 0}}{\tau}
$$

where $\tau$ is the relaxation time and can be found by integrating equation (A10) as

$$
\int_{\mathrm{tho}}^{\epsilon_{\mathrm{h}}} \frac{\delta \epsilon_{\mathrm{h}}}{\epsilon_{\mathrm{h}}}=\int_{0}^{1} \frac{\delta t}{\tau}
$$

simplifying we get

$$
\tau=\frac{k T r R}{D \Omega}\left(\frac{3 K_{\mathrm{p}}+4 \mu_{\mathrm{m}}}{36 K_{\mathrm{p}} \mu_{\mathrm{m}}}\right) .
$$

For the present case of an inclusion sitting on a grain boundary, dislocation subcell network, or within the grains the appropriate diffusivity would be that for grain boundary diffusion, dislocation pipe diffusion, or the bulk diffusion, respectively. The characteristics distance $r$ would then be the distance between dislocation segments in the grain boundary, the subcell, and the interparticle spacing, respectively. For the case of a small indium particle of $R$ equal to $1 \mu \mathrm{m}$ embedded in a well annealed matrix a relaxation time of $8 \times 10^{6} \mathrm{~s}$ may be calculated from equation (A12) where $T$, the indium melting temperature is $429 \mathrm{~K}, \Omega$ is equal to $24 \times 10^{-30} \mathrm{~m}^{3}, r$ is equal to $2.4 \mu \mathrm{m}, D$ is the bulk diffusivity of $8.9 \times 10^{-22} \mathrm{~m}^{2} / \mathrm{s}$, and $K_{p}$ and $\mu_{\mathrm{m}}$ are approximated as $12 \times 10^{9} \mathrm{~N} / \mathrm{m}^{2}$ and $25 \times 10^{9} \mathrm{~N} / \mathrm{m}^{2}$, respectively. 